\title{
A Review on Automatic Closed Loop Speed Control of a DC Motor
}

\author{
Ms.S.R.Bhagwatkar ${ }^{1}$, Mr.A.P. Dhande ${ }^{2}$ \\ Student, Dept. of Electronics and Telecommunication, P.R.Patil college of Engg. and Technology, Amravati, India ${ }^{1}$ \\ Professor, Dept. of Electronics and Telecommunication, P.R.Patil college of Engg. and Technology, Amravati,India ${ }^{2}$
}

\begin{abstract}
The DC motor is an attractive piece of equipment in many industrial applications requiring variable speed and load characteristics for its ease of controllability. The speed control of DC motor is very crucial in application where precision and protection are of essence. Purpose of motor speed controller is to take error correcting signal representing the required speed and to drive a motor at fix speed. Embedded based speed control system consists of electronic component and some sensors. In this work, development of hardware and software of the closed loop DC motor speed control system have been explained and illustrated. The desired objective is to achieve a system with the constant speed at variable load condition. That means motor will run at a fixed speed instead of varying with amount of load.
\end{abstract}

Keywords: DC Motor, MOSFET, Microcontroller, IR Sensor.

\section{INTRODUCTION}

Microcontroller based speed control system consist of this paper, implementation of the ATmega128 microcontroller for speed control of DC motor fed by a MOSFET has been investigated. The MOSFET is driven by a high frequency PWM signal. By using contact less IR (Infrared) sensors we can measure the speed of motor. Controlling the PWM duty cycle is equivalent to controlling the motor terminal voltage, which in turn adjusts directly the motor speed. This work is a practical one and high feasibility according to economic point of view and accuracy. In this work, development of hardware and software of the close loop dc motor speed control system have been explained and illustrated. The desired objective is to achieve a system with the constant speed at any load condition. That means motor will run at a fixed speed instead of varying with amount of load. Speed control of dc motor could be achieved using mechanical or electrical techniques. In the past, speed controls of dc drives are mostly mechanical and requiring large size hardware to implement

The development has launched these drives back to a position of formidable relevance, which were hitherto predicted to give way to ac drives. Some important applications are: rolling mills, paper mills mine winders, hoists, machine tools, traction, printing presses, textile mills, excavators and cranes.

The main objective of this work is to become familiar with the design and implementation of both software and hardware of a microcontroller based closed loop speed control of DC motor and to give senses of occurring overload condition to the operator at overload condition. The purpose of a motor speed controller is to take a signal representing the required speed, and to drive a motor at that speed.

Copyright to IJARCCE

DOI 10.17148/IJARCCE.2015.4128

\section{LITERATURE REVIEW}

Atul Kumar Dewangan, Nibbedita Chakraborty, Sashi Shukla, Vinod Yadu (2012), have design a system, based on the speed controlling of a DC motor, with a constant speed at any load condition. For that purpose they use PWM and DC chopper.

In another paper by Hamid Saeed Khan and Muhammad Bilal Kadri (2013), they have presents an implementation of digital PI controller on an 8-bit microcontroller. This PI controller is tested for the plant model of DC motor by hardware-in-loop simulation technique. In this HIL simulation, the PI controller is implemented on a microcontroller and the plant model is in simulation environment and the digital PI controller is tested on DC motor speed model by hardware-in-loop simulation technique.In this HIL simulation, the PI controller is implemented on a microcontroller and the plant model is in simulation environment. The PD, PI and PID controllers are widely used in industrial control systems. These controllers calculate an "error" value as the difference between a measured plant output and a desired set-point. The controller attempts to minimize the error by adjusting the plant control input. The main reason of using ATMEL 8051 microcontroller is its easy use and low cost. This digital PI controller can be tested on any plant, but need to be tuned with respect to that plant by any tuning method. In this paper, the digital PI controller is tested on DC motor speed model by hardware-in-loop simulation technique.

ManuelGuerreiro and Daniel Foito (2007), have design a model in which speed was controlled using sliding mode with a first order differential equation based on the speed error. The result of the switching function was integrated with a current limitation using a logic equation. The current limitation assures the machine protection and the output of the logic block is the signal of the voltage to apply on the motor armature. Instead to measure the rotor speed it was 
analytically inferred an external torque and speed observer. The motor is fed by a classic insulated gate bipolar transistor converter module. All gating signals for power switches are determined at every sample instant by a single microcontroller, which collects information and analyse voltage and current data from the motor to perform the necessary speed and torque estimation.

Jeetender Singh Chauhan and Sunil Semwal (2013), have shown in their paper, how a RS-232 is used to control speed of DC motor. In this paper, PWM based speed control of DC motor through RS232 with PC goal of this as Role of electrical drives is a major concern in industrial automation.Having intelligence PC available to control operation of speed of motor which can increase productivity in broad range of industry. Personal computers or Laptops are working on Register Level while our controller is working on TTL so we have to use a level shifter that is MAX232 IC which can change the platform for serial communication. This software provide variable baud rate for operation, and connect PC to MAX232 using serial cable.

We can definitely control Speed of a motor with a Potentiometer, but this wastes power and energy in theform of heat across the resistor, as having a resistor in series does have a voltage drop, hence heat loss. A microcontroller-based PWM solution uses fewer components and has flexibility of varying the duty cycle and frequency. Having a PWM, means you do not have a resistor in series, meaning no waste in the form of heat. We just shuttle the Motor between ON \& OFF, and the average gives us the voltage. So, no waste of power is there.

\section{III.METHODOLOGY}

We will design a dc motor with fixed speed control system, which has high precision, reliability and adaptability for different motor ratings with good speed response. That means motor will run at fixed speed at any load condition. It will not vary with the amount of load. The software is made in such a way that even an unskilled operator can operate it. This system describes the design and implementation of the Automatic Closed Loop Speed Control of DC Motor, that controls the speed of a DC motor by using PWM and MOSFET. In implementing this work frequency, independent PWM output with variable duty cycle that can vary from $0 \%$ to $100 \%$ is generated. Furthermore, an LCD display was fabricated to display the output; this kind of setup provides a complete user interface unit. Hence the system is complete stand-alone and user friendly.

In case of sudden load drops, the speed of the motor will be very high. As a result, output voltage will be also very high. Therefore, controller unit will sense output voltage and will compare with the desired level of voltage. In case of excessive load, output voltage does not matches the desired level then microcontroller will send a message "OVERLOAD" using the LCD, so that the user can understand the condition and hence reduce the load of the motor. 
DC motor plays a significant role in modern industrial. These are several types of applications where the load on the DC motor varies over a speed range. These applications may demand high-speed controlaccuracy and good dynamic responses. In home appliances, washers, dryers and compressors are good examples. In automotive, fuel pump control, electronic steering control, engine control and electric vehicle control are good examples of these. In aerospace, there are a number of applications, like centrifuges, pumps, robotic arm controls, gyroscope controls and so on.

\section{IV.CONCLUSION}

We will design a dc motor with fixed speed control system, which has high precision, reliability and adaptability for different motor ratings with good speed response. That means motor will run at fixed speed at any load condition. It will not vary with the amount of load. The software is made in such a way that even an unskilled operator can operate it. This system describes the design and implementation of the Automatic Closed Loop Speed Control of DC Motor, that controls the speed of a DC motor by using PWM and MOSFET. In implementing this work frequency, independent PWM output with variable duty cycle that can vary from $0 \%$ to $100 \%$ is generated. Furthermore, an LCD display was fabricated to display the output. This kind of setup provides a complete user interface unit. Hence the system is complete stand-alone and user friendly.

\section{ACKNOWLEDGMENT}

It is a matter of great pleasure by getting the opportunity of highlighting a fraction of knowledge. It's the feeling of immense pleasure for me to express sense gratitude to my family members and Mr. A.P.Dhande for his encouragement, enlighten comments throughout the proposed work. His appreciative suggestions and positive comments always motivated for putting complete efforts on study during project report.

Thankful to all faculty members who always supports for this proposed work.

\section{REFERENCES}

[1] Atul Kumar Dewangan, Nibbedita Chakraborty, Sashi Shukla, Vinod Yadu," PWM Based Automatic Closed Loop Speed Control of DC Motor" International Journal of Engineering Trends and Technology- Volume3Issue2- 2012.

[2] Jeetender Singh Chauhan, Sunil Semwal, International Journal of Engineering Research and Applications. "Microcontroller Based Speed Control of DC Geared Motor Through RS-232 Interface With PC" Vol. 3, Issue 1, January -February 2013.

[3] Hamid Saeed Khan, Muhammad Bilal Kadri, "DC Motor Speed Control by Embedded PI Controller with Hardware-in-loop Simulation", Electronics and Power Engineering Department, PN Engineering College.2013.

[4] Manuel Guerreiro, Daniel Foito,"A Microcontroller Sensor-less SpeedControl of a Direct Current Motor"2007.

[5] Y. S. E. Ali, S. B. M. Noor, S. M. Uashi and M. K Hassan. "Microcontroller Performance for DC MotorSpeedControl System" National Power and Energy Conference (PECon) 2003 Proceedings, Bangi, Malaysia.

[6] Vadim I. Utkin, "Sliding mode control design principles and applicationsto electric drives", IEEE Transactions On Industrial Electronics, Vol. 40,No. 1, pp. 23-36, February 1993.

Copyright to IJARCCE
7] John Y. Hung, WeibingGao, James C. Hung, "Variable structure control:a survey", IEEE Transactions On Industrial Electronics, Vol.40, No. 1,pp. 2-22, February 1993

[8] A. Cordeiro, D. Foito, M. Guerreiro, "A sensorless speed control Systemfor an electric vehicle without mechanical differential gear" IEEEMELECON 2006, May 16-19, Benalmádena (Málaga), Spain pp. 1174-1177.

[9] Gopal K. Dubey, "Fundamentals of Electric Drives",.Narosa Publishing House New Delhi,1989.

[10] Krishnan and Thadiappan, "Speed Control of DC Motor Using Thyristor 0" „1 Converter," IEEE TrOllS., Vol, T-IECI, pp, 391 399, Nov. 1976 